\title{
Impact of Offenses in Alternative Sentences
}

\author{
PhD. Cand. Adrian Leka
}

\begin{abstract}
Alternative sentences prevent violence and help the community. Prison is known as a place where people are confined and restricted from personal freedom. There are a lot of crime categories where exists different type of offenders, but on the other hand there are a lot of solutions for each of them .Imprisonment is not always the only way to punish an offender. As alternative sentences we can list some of them: a suspended sentence, probation, fines, restitution, community service and deferred adjudication/pretrial diversion. Alternative sentences can be different based on the type and harshness of the crime, the effect of the crime on the victims, the age of the defendant, the defendants criminal history and the defendants remorse. This is decided by the judge, court. Below we will explain some different types of alternative sentences in more details.
\end{abstract}

Keywords: impact, offenses, alternative, sentences

\section{Introduction}

\section{Suspended Sentences}

Often happens that the defendants prison sentence is "suspended". This is used especially in cases involving not serious crimes or for first-time offenders. There are some different kinds of suspended sentences.

A sentence can be suspended by the judge before it is imposed or executed. If the judge suspend a sentence prior to the imposition, it means that the judge deviate from outrunning the sentence at all. When the judge is informed by the prosecutor or probation department that during the suspended sentence the defendant has violated any of the rules that led him/her to the suspended sentence, the judge own the prudence to order the defendant to serve the original sentence.

Suspended sentences are divided in two categories: unconditional or conditional. The unconditional suspended sentence just suspend the sentence.

When suspended sentence is conditional, the judge can hold off from either imposing or executing the conviction for as long as the defendant accomplishes the condition of the suspension. If an defendant violates any of the goals of a conditional suspension, the judge can impose or execute a sentence.

\subsection{Sentences Suspended Prior to the Imposition}

When a judge suspends the imposition of a sentence, he has declined to hand down a sentence, but this doesn't mean to not have the right to do so in the future.

As long as the suspension is for certain amount of time and this period of time is reasonable, the court has the power to suspend a sentence prior to its imposition. This power of the court is not part of all jurisdictions. There must be a law, in some jurisdictions, that authorize suspended sentences before a judge can suspend a sentence.

When the imposition of a sentence has been suspended by the court, they can cancel the suspension and impose any sentence that was available to it at the time of conviction. This happens when the offender doesn't fulfill the conditions of the suspension. The case will be reviewed by a judge and then will be decided whether or not to cancel the suspension and what sentence to impose if it is cancelled. 


\subsection{Sentences Suspended Prior to the Execution}

Even when the judge would refuse imposing the sentence, often happens that they can suspend sentences before they will be executed, that means the defendant does not have to serve it immediately at all.

As we saw above most of the courts have the power to suspend sentences prior to their execution. Just like the sentences suspended prior to the imposition, not every jurisdiction give to the courts the prudence to do this.

Often happens that jurisdictions order judges to suspend sentences immediately after they are done.

Sentences suspended prior to execution can also be either conditional or unconditional. If the suspended sentence is conditional, the judge can cancel the suspension if the defendant violates any of the conditions.

\section{Probation}

Another way of sentencing a defendant except of imprisonment, is probation. This type of sentencing makes possible to defendant to be part of community but with the same freedom the defendant owned before. As probation is accompanied with conditions that limit the freedom of the defendant, if happens that defendant violates any of these conditions, the court have the capability to cancel the probation.

Courts receive probation for first-time or not serious enough offenders. There are statutes that determine when probation is possible, but most important is up to the sentencing judge to determine if agree the probation.

Sentencing judges must stay within the statutory limits in receiving probation ,even they have this prudence.

Probation has three primary goals:

To help offenders change, rehabilitate

To protect the community by assisting judges in sentencing and supervising defendants

To protect and support crime victims

When a judge has received the probation, what happen then passes into the probation officers jurisdiction ,that monitor the probationers compatibility with conditions of the probation.

\subsection{Probation Conditions}

As we said the probation is always accompanied by conditions. A defendant must respect and fulfill these conditions else the court would impose an imprisonment or add more restrictive conditions during the probation. Judges set these conditions in order to fulfill the goals we mentioned above.

Usually, courts have the prudence to set probation conditions but this doesn't mean that judges can set whatever they want. The conditions must be reasonable, that mean the conditions cannot be punitive ,unclear or arbitrary. The conditions must protect the public. When a judge want to set special conditions, these must be in compatibility with the conditions of probation and with importance of how serious was the crime.

Condition are set by the judge, but the people responsible for enforcing them are probation officers. If probation officer find any cause or believe that the defendant has violated any probation condition, then the judge can cancel the probation and impose a prison sentence for him/her.

\subsection{Probation Revocation}

As we said that the probationers freedom is restricted, however, he/she has to go through e procedural process

In case that the court has decided for e probation revocation, the probationer owns the right for being notified of proposed revocation and guide a hearing of the issue, to indicate at the hearing, to present supporting witnesses and let them confront .At the end the probationer has the right to get a written statement that explains the reasons of the revocation. 
The violation of any condition can be reason for revocation of probation. The violated condition must be effectual and important. If a condition is not found within the period of time decided from the court to be unreasonable then violation of that condition will not be a reason for revocation.

\section{Fines}

All of us have had to pay a fine at some point, as a parking ticket, or anything like this. People that used to be incriminated in more serious crime in many cases have to pay fines, even thought the amount of the fine has a certain value. By imposing a criminal fine the offender can be punished, the state can be helped to compensate for the offense and any criminal act can be taken away.

When someone is blamed for a crime, the sentencing judge has the prudence to give him a criminal fine. The fine can be given instead of probation or the trip to prison.

It depends on how serious was the crime, to decide a criminal fine instead of prison or probation. Sometime the fines are put without probation or accompanying time for low serious crimes or first time offenders. Even if the defendant pay the fine or finish the probation time, his occurrence will still be considered as a criminal history.

\subsection{Fines vs. Restitution}

As we all know the criminal fines and restitution look like one another because for both of them you have to pay ,but they have also their differences. The criminal fines are paid to the government but the restitution should be paid to the crime victims .

\section{Restitution}

The defendant has to pay a certain amount of money to the crime victim , that is called restitution. In cases where criminal victims have financial problems as a result of the crime ,the judge decides to order the restitution. The restitution sentence pays all the expenses that has been caused by defendant to crime victims.

Restitution can be proposed as a sentence instead of probation or prison, and also as a sentence in its own. If you are ordered by the court to pay restitution, it means that you are ordered to pay all the expenses for damaging the state or victims. Restitution is not given only in cases when you are able to pay, it doesn't consider this fact at all.

Most of the cases the defendant are ordered to pay restitution as one part of the sentence, such as probation, prison, community service etc. Often happens that the defendant accept the crime and the victim will be completely compensated for damage and the criminal charges are dropped . This type of dealing is called a "civil compromise."

\subsection{Restitution vs. Fines}

As we told above fine is money paid to the state but restitution is money that the offender pays to the victim of crime or to the state if has been its damage. The defendant is ordered to replace stolen or damaged property ,to compensate the crime victims for physic injuries, medical and psychological treatment costs, or to pay funeral and other costs if the victim passes away.

\section{Court Ordered Community Service}

In this type of sentencing the court order the offender to work for community for e complete or partial of fines, probation or imprisonment. Usually courts like this type of sentencing because it reduces the number of prisoners, the community take a lot of benefits and perhaps teach the offender the ethical behavior.

Not always community service fits with the criminal category the offender is accused of so in most cases the court have to find something that the offender has capability to do.

Despite the fact that offenders freedom is restricted sometimes they are given the possibility by the judge to choose what they can do. In this case someone has to verify if the defender completed his/her hours of work. This can be done by the judge or the any community agency. Another way to verify is the organization where defendant is doing his/her sentence.

\section{Deferred Adjudication / Pretrial Diversion}


There are many cases that demonstrate the qualification of some offenses or offenders in programs that dismiss the case again the defendant after ending the conditions that have to. All these types of programs make possible for defendant to not go through the prosecution channels but the specific conditions that was charge for. When the defendant complete the conditions successfully, the court and prosecution will dismiss the charge.

The purpose of this kind of program is to make able the defendants rehabilitation and to prove that they can behave correct and with responsibility. What they carry off in this case is their freedom and dismissed charges.

These type of programs are applied for first time offenders, or not serious enough crimes. The defendant is required to follow some conditions that include form of counseling ,probation and also good behavior throughout the program.

These kinds of program are divided in two types: the first type requires from the defendant to plead guilty for the accusation and the second that do not. The first one is known as deferred adjudication and the second is known as pretrial diversion.

\subsection{Pretrial Diversion}

Pretrial Diversion is a program for first time offenders that gives them the possibility to avoid being marked for a criminal conviction for further in their life. There are a lot of names used to describe pretrial diversion, such as:

deferred prosecution

withheld adjudication

good behavior

pretrial intervention

withheld sentencing

withdraw and file

Pretrial diversion, despite the detail that vary from one state to another one, usually has a basic structure. When a defendant is charged for the first time ,for a low serious crime and appears to be a person who do not look like tends to be repeat offender may be given the possibility to follow this program. If the defendant accept to plead guilty to the criminal offense, the judge will not command any penalty to the person. The prosecutor stop the case and the defendant has to meet with specific conditions. These conditions include probation, counseling and community service, among others.

In these cases the discretion to put the defendant's case in this program belong to the prosecutor. The acceptability requirements will be set by the statue, but will be on prosecutor's hands the ultimate decision to allow or not the defendant enter in this program.

Usually happens that the prosecutors have to get the acceptance of crime victim before putting the defendant in the pretrial diversion program. Being involved previously by the defendant in this kind of program make him/her inappropriate to get it for the second time .

When the offender does not meet the conditions that were appointed to him/her, the prosecutor will send the case at the court as no evasion had settled down.

This type of program is a great way to keep you away from criminal conviction for one -time mistake or not serious enough crime. Everyone who gets arrested and doesn't have a criminal history, should ask for pretrial diversion if the offender doesn't want to go to the court.

\subsection{Deferred Adjudication}

After the defendant has plead guilty, the deferred adjudication begins .It often involves probation, treatment programs and some type of community supervision. As the pretrial diversion, the court will set a number of conditions that the defendant must meet. If the defendant meets the conditions, the charges are dismissed.

If, the defendant does not fulfill the conditions successfully, the court will enter a trial and order a punishment. 
What makes the difference between a deferred adjudication and a pretrial diversion is that, , a defendant must first plead guilty in a deferred adjudication. If the defendant does not fulfill the conditions of the deferred adjudication, the state does not have to put the defendant back on trial for the crime. The court simply enters its judgment and sentence.

In a pretrial diversion, if the defendant fails to meet the conditions of the program, the state must place the defendant on trial, since there was no prior guilty plea.

\section{Bibliography}

[1] The Constitution of the Republic of Albania

[2] The Penal Code of the Republic of Albania

[3] Criminal Procedure Code of the Republic of Albania

[4] "Juridical Tribune", 2004, no. 46, H. Bano "Execution of Prison Sentences"

[5] "Juridical Tribune ", 2005, no. 55, H. Islam "Alternatives to imprisonment"

[6] "Legal Life" no. 1 Tirana March 2009 H. Islam "Execution of alternative sentencing and probation service." 